\title{
Transient Stability Enhancement using Variable Speed Wind Turbine with Direct Drive Synchronous Generators
}

\author{
R. Jeevajothi and D. Devaraj
}

\begin{abstract}
This paper investigates about the enhancement in grid transient stability while integrating the large-scale variable speed wind turbine (VSWT) with DDSG. A dynamic modeling and simulation of a grid connected VSWT with DDSG with controllable power inverter strategies suitable for the study was developed, tested and verified. This dynamic model with its control scheme can regulate real power, maintain reactive power, and generate voltage at different wind speeds. For this paper, studies were conducted on a standard IEEE 9 bus system augmented by a radially connected wind power plant (WPP) which contains 28 VSWTs with controllable power inverter strategies. Also it is proved that it has the potential to control the rotor angle deviation and increase the critical clearing time during grid disturbance with the help of controllable power inverter strategy.
\end{abstract}

Index Terms-VSWT, DDSG, rotor angle deviation and critical clearing time, transient stability, grid connected.

\section{INTRODUCTION}

Installed wind power generation capacity is continuously increasing. Wind power is the most quickly growing electricity generation source with a $20 \%$ annual growth rate for the past five years. Variable speed operation yields 20 to 30 percent more energy than the fixed speed operation, reduces power fluctuations and improves reactive power supply [1]. There are many papers dedicated to dynamic model development of variable speed wind turbine DDSGs $[2,6]$. Taking a IEEE three-machine, nine-bus system [3], we attach the WPP system radially through a transmission system and transformers at bus 1 in Fig. 1.The equivalent WPP has a set of wind turbines connected in daisy-chain fashion. The DDSG is operated in a variable speed with capability to control the voltage at the regulated bus at constant power factor. The 28 wind turbine generators have a combined rating of 100MW. The impact of wind-generation technology on power system transient stability is also shown in [4], [5].

\section{Modeling}

Fig.1presents a schematic diagram of the proposed VSWT with DDSG connected to the grid.

\section{A. Wind Turbine}

The wind turbine is described by the following equations (1) (2) and (3).

Manuscript received February 21, 2012; revised March 20, 2012.

The authors are with the department of Electrical and Electronics Engineering , Kalasalingam University, Krishnankoil, Virudhunagar district, Tamilnadu, INDIA (e-mail: rjeeva.jyothi.@ gmail.com, deva230@yahoo.com )

$$
\begin{gathered}
\lambda=\frac{\omega_{M} R}{V_{W}} \\
P_{M}=\frac{1}{2} \rho \pi R^{2} C_{P} V_{W} \\
T_{M}=\frac{P_{M}}{\omega_{M}}=\frac{1}{2} \rho \pi R^{5} C_{P} \frac{\omega_{M}^{2}}{\lambda^{3}}
\end{gathered}
$$

where $\lambda=$ tip speed ratio

$\omega_{M=}$ Mechanical speed of wind turbine $[\mathrm{rad} / \mathrm{s}]$

$\mathrm{R}=$ Blade radius $[\mathrm{m}]$

$V_{\mathrm{W}=\text { wind speed }[\mathrm{m} / \mathrm{s}]}$

$P_{M}=$ Mechanical power from wind turbine $[\mathrm{kW}]$

$\rho=$ Air density $\left[\mathrm{kg} / \mathrm{m}^{3}\right]$

$C_{P}=$ Power coefficient

$T_{M}=$ Mechanical torque from wind turbine $[N \cdot \mathrm{m}]$

The mechanical torque obtained from equation (3) enters as the input torque to the synchronous generator, and is driving the generator. $\mathrm{C}_{\mathrm{P}}$ may be expressed as a function of the tip speed ratio (TSR) $\lambda$ given by equation (2)

$$
C_{P}=(0.44-0.0167 \beta) \sin \frac{\pi(\lambda-2)}{13-0.3 \beta}-0.00184(\lambda-2) \beta
$$

where $\beta$ is the blade pitch angle. For a fixed pitch type the value of $\beta$. is set to a constant value $4.5^{0}$

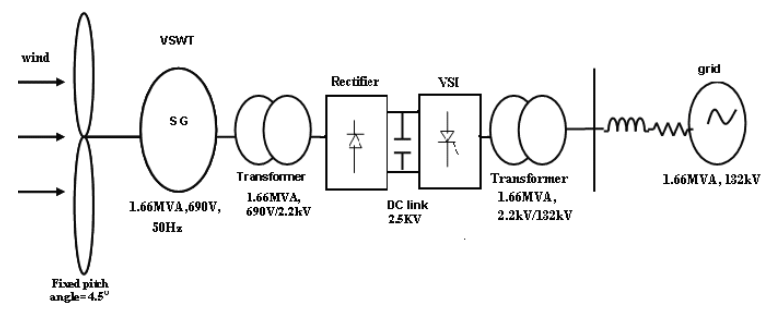

Fig. 1. Schematic diagram of the proposed VSWT driven synchronous generator connected to the grid

\section{B. Synchronous Generator}

The DDSG is equipped with an exciter identical to IEEE type 1 model [7 ].The exciter plays a role of helping the dc link to meet the adequate level of inverter output voltage as given in (5) below

$$
V_{d c}=\frac{2 \sqrt{2} \cdot V_{A C_{-} R M S}}{D_{R M S}}
$$


where $V$ AC_RMS is RMS line to neutral voltage of the inverter and $D_{\mathrm{MAX}}$ is maximum duty cycle. The exciter plays a role of meeting the dc link voltage requirement.

\section{Power Electronics Control}

This consists of an uncontrolled six-diode rectifier and a six-IGBT voltage source inverter, which is simple, cost-effective and widely used for industrial applications [8]. The VSI includes a $L C$ harmonic filter at its terminal to reduce harmonics it generates. The rectifier converts ac power generated by the wind generator into dc power and power control has to be implemented by the VSI. A current-controlled VSI can transfer the desired real and reactive power by generating an ac current with a desired reference waveform

\section{ANALYSIS OF TRANSIENT STABILITY}

Analysis of transient stability of power systems involves the computation of their nonlinear dynamic response to large disturbances, usually a transmission network fault, followed by the isolation of the faulted element by protective relaying. In these studies, two methods ie. calculation of critical fault clearing times and calculation of rotor angle deviation are used for assessing dynamic performance of the power system following a large disturbance.

\section{A. Critical Clearing Time}

The critical clearing time (CCT) is the maximum time interval by which the fault must be cleared in order to preserve the system stability.

Generating units may lose synchronism with the power system following a large disturbance and be disconnected by their own protection systems if a fault persists on the power system beyond a critical period. The critical period will depend on number of factors. The nature of the fault (e.g. a solid three phase bus fault or a line to ground fault midway on a transmission circuit);

- The location of the fault with respect to the generation; and;

- The capability and characteristics of the generating unit.

The calculation of the critical clearing time for a generating unit for a particular fault is determined by carrying out a set of simulations in the time domain in which the fault is allowed to persist on the power system for increasing amounts of time before being removed.

\section{B. Rotor Angle Deviation}

Rotor angle deviation assessment of wind power generator is one of main issues in power system security and operation.

\section{Simulation Results}

The modeled VSWT with DDSG is connected to a IEEE 9 bus system with fault applied near by bus-7.The modeling of the VSWT with DDSG is implemented in MATLAB. Stable grid interface requires a reliable tool PSAT/Matlab for simulating and assessing the dynamics of a grid connected variable speed wind turbine driven synchronous generators
[9]. The capacity of the VSWT with DDSG is chosen to be 1.66 MVA and real power 1.5 MW. The rated speed of the rotor is chosen to be $40 \mathrm{rpm}$. The rated wind speed is $15 \mathrm{~m} / \mathrm{s}$. the cut-in and cut-out speeds are $4 \mathrm{~m} / \mathrm{s}$ and $23 \mathrm{~m} / \mathrm{s}$ respectively. Here, the system is simulated under 8 and $7.5 \mathrm{~m} / \mathrm{sec}$. is shown in Fig.2. The switching frequency of the grid interface inverter is $1.040 \mathrm{kHz}$. The capacitor value of grid interface rectifier is $2500 \mu \mathrm{F}$ and d.c link voltage is 2.5 $\mathrm{kV}$. The generated voltage of synchronous generator is $0.69 \mathrm{KV}$. The transformer rating of grid connected side is $2 \mathrm{kV} / 130 \mathrm{kV}$. The p.u voltage magnitude of primary of the transformer is 0.99 p.u.. The grid voltage is $130 \mathrm{kV}$.

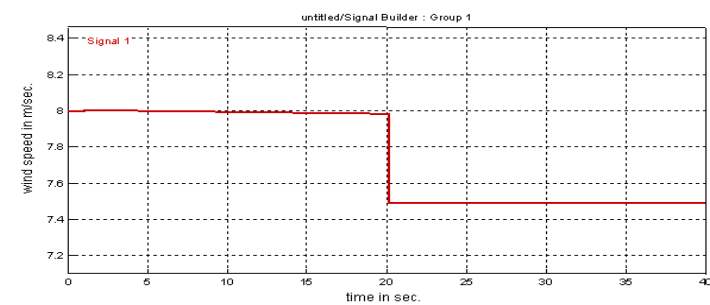

Fig. 2. Wind speed

Fig. 3-9 represents the simulation waveform of the modeled VSWT with DDSG.

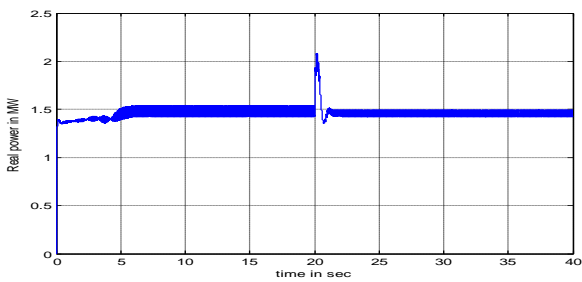

Fig. 3. Simulation waveform of real power of VSWT

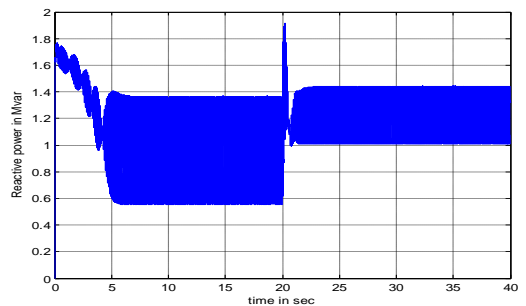

Fig. 4. Simulation waveform of reactive power of VSWT

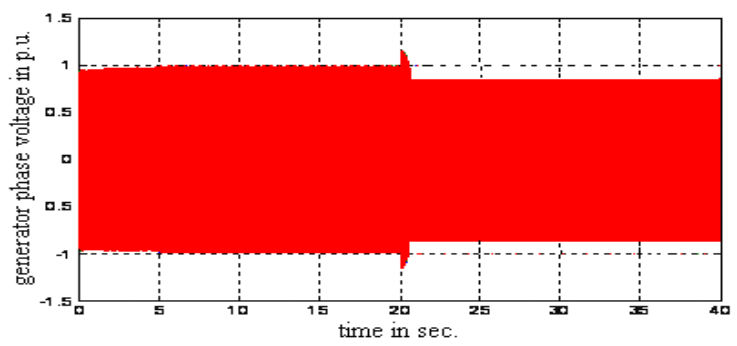

Fig. 5. Simulation waveform of generated phase voltage in pu of VSWT with DDSG

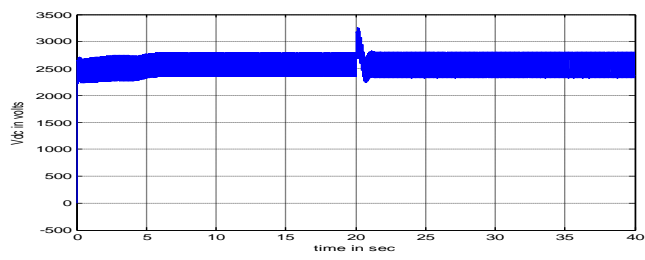

Fig. 6. Simulation waveform of d.c link voltage $2.5 \mathrm{KV}$ of VSWTwith DDSG 


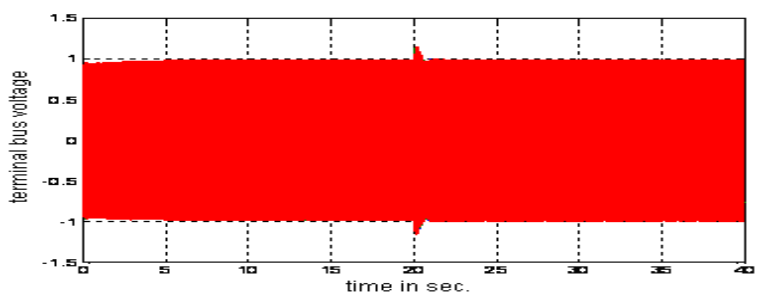

Fig. 7. Phase voltage in p.u in grid side of VSWT with DDSG

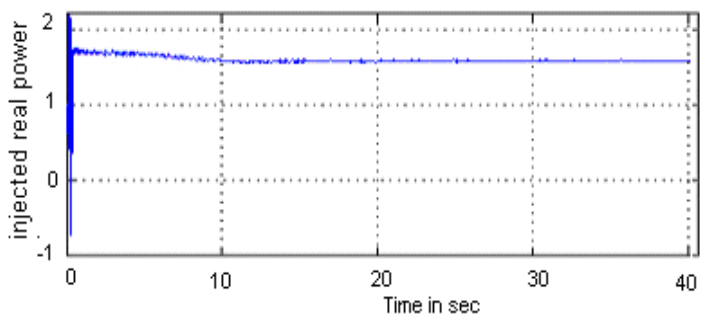

Fig. 8. Simulation waveform of real power $1.5 \mathrm{MW}$ in grid side in p.u of VSWT with DDSG

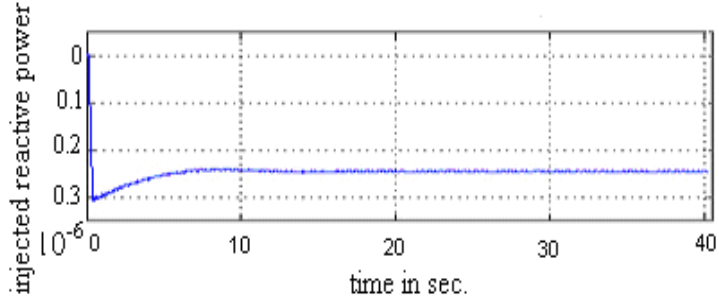

Fig. 9. Simulation waveform of injected 0.25 MVAR reactive power in grid side in p.u of VSWT with DDSG

Fig.10 represents the voltage under line fault near bus 7 with only conventional synchronous generators.

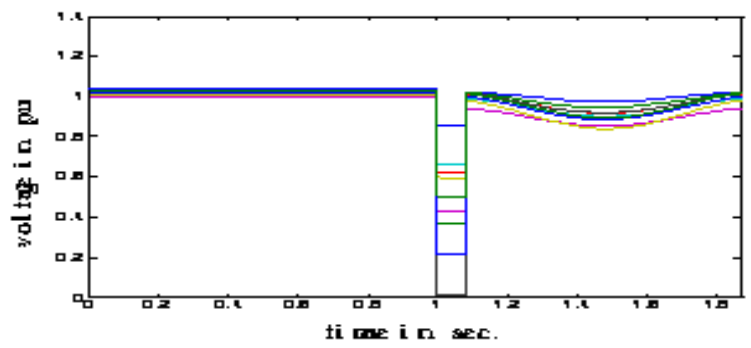

Fig. 10. Voltages for line fault near bus 7 with only conventional synchronous generators

From this graph, the critical fault clearing time is calculated to be $0.083 \mathrm{sec}$. ( 4.15 cycles).

Fig. 11 represents the voltage under line fault near bus 7 with WPP at bus-1.

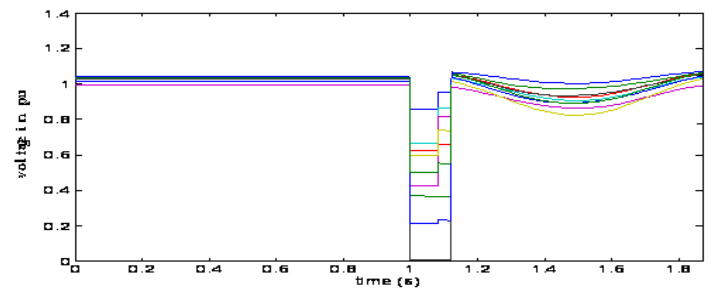

Fig. 11. Voltages for line fault near bus 7 with a WPP at bus 1

From this graph, the critical fault clearing time is calculated to be 0.12 sec.( 6 cycles $)$. When comparing the results in Fig. 10 and Fig. 11, it is found that the critical fault clearing time has increased by 1.85 cycles with WPP. Also the voltage level also has improved above $1 \mathrm{pu}$. which can be seen in Fig.11?

Fig. 12 represents the rotor angle deviation under line fault near bus 7 with only conventional synchronous generators. It can be seen that the maximum rotor angle deviation is $100^{\circ}$.

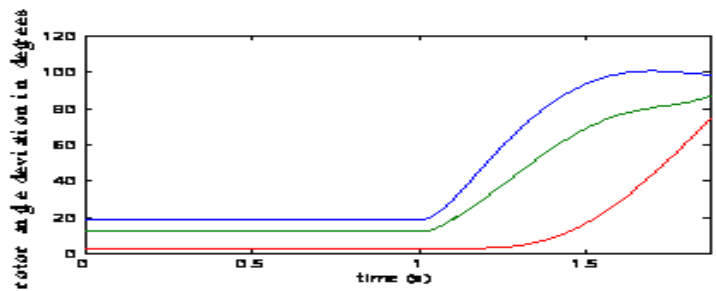

Fig. 12. Rotor angle deviation for line fault near bus 7 with only conventional synchronous generators.

Fig. 13 represents the rotor angle deviation under line fault near bus 7 with WPP at bus-1.It is found that the maximum rotor angle deviation is $90^{\circ}$.

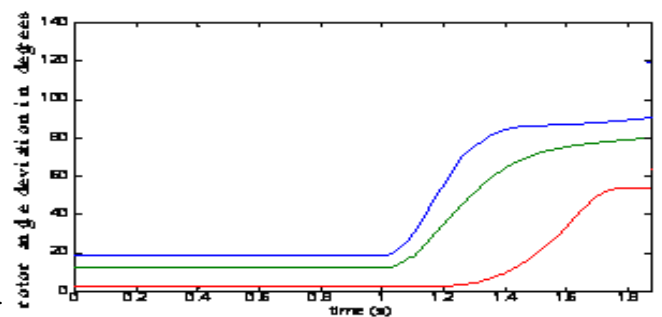

Fig. 13. Rotor angle deviation for line fault near bus7 with a WPP at bus 1

When comparing the results in Fig. 12 and Fig. 13 rotor angle deviation has reduced by $10^{\circ}$ when WPP is connected at bus-1.

Fig. 14 represents the real power under line fault near bus 7 with only conventional synchronous generators.

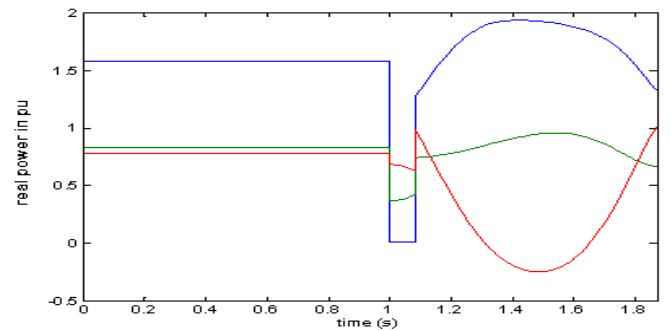

Fig. 14. Real power for line fault near bus 7 with only conventional synchronous generators

Fig. 15 represents the rotor angle deviation under line fault near bus 7 with WPP at bus-1.

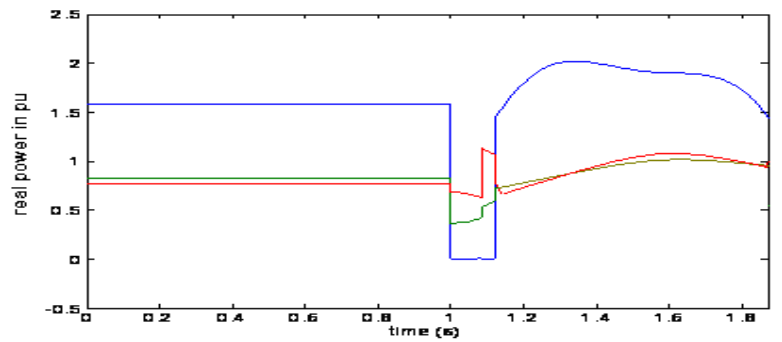

Fig. 15. Real power for line fault near bus 7 with a WPP at bus 1 .

When comparing the results in Fig. 14 and Fig. 15, it is found that the real power in all generators of power system network has been maintained above 1pu with WPP. 
Fig.16 represents the reactive power under line fault near bus 7 with only conventional synchronous generators.

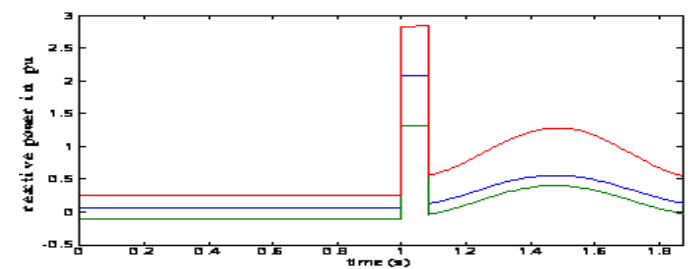

Fig. 16. Reactive power for line fault near bus 7 with only conventional synchronous generators.

Fig. 17 represents the reactive power under line fault near bus 7 with WPP at bus-1.

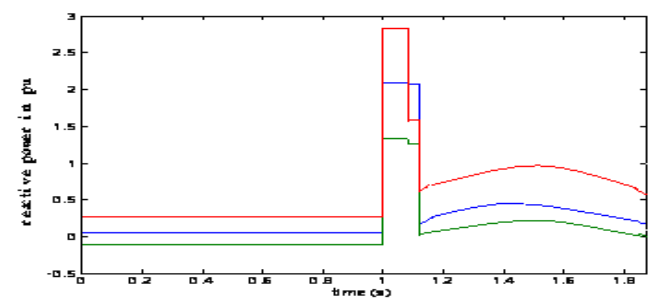

Fig. 17. Reactive power for line fault near bus 7 with a WPP at bus 1 .

When comparing the results in Fig. 16 and Fig. 17, it is found that the reactive power supply has not been deviated much with WPP.

\section{CONCLUSION}

A dynamic model of a VSWT with DDSG and power electronic interface was implemented in MATLAB. The VSWT component models and control scheme were built by using user-defined and built-in components provided in the software. Fault tests were carried out to study the transient behaviors of real power, reactive power, voltage, critical clearing time and rotor angle deviation of a VSWT under variable wind speed conditions. Before interfacing with grid comprehensive impact studies are necessary. The work illustrated in this study may provide a reliable tool for evaluating the performance of a VSWT with DDSG and its impacts on power networks in terms of dynamic behaviors; therefore, serve as a preliminary analysis for actual applications.

\section{REFERENCES}

[1] “20\% Wind Energy by 2030 - Increasing Wind Energy's Contribution to U.S. Electricity Supply,” U. S. Department of Energy May 2008. DOE/GO-102008-2567, http://www1.eere.energy.gov/windandhydro/pdfs/41869.pdf

[2] H. Slootweg, Wind Power: Modeling and Impact on Power S system Dynamics, Ph.D. Thesis, Technical University Delft, Delft, the Netherlands, 2003

[3] P. W. Sauer and M. A. Pai, "Power System Dynamics and Stability," ISBN 1-58874-673-9, Stipes Publishing L.L.C, Champaign, IL, 2006.

[4] E. Muljadi, T. B. Nguyen, and M. A. Pai, "Impact of Wind Power Plants on Voltage and Transient Stability of Power Systems," IEEE Energy 2030, Atlanta, Georgia, USA, 2008.

[5] C. Samarasinghe and G. Ancell, "Effects of large scale wind generation on transient stability of the New Zealand power system," IEEE Power and Energy Society, General Meeting, 2008.

[6] A. Petersson, T. Thiringer, L. Harnefors, T. Petru, "Modeling and Experimental Verification of Grid Interaction of a DFIG Wind Turbine," IEEE Transactions on Energy Conversion, vol. 20, pp. 878 $-886,2005$.

[7] J. G. Slootweg, S. W. H. d. Haan, H. Polinder, and W. L. Kling, "General model for representing variable speed wind turbines in power system dynamics simulations," IEEE Trans. Power Systems, vol. 18, no.1,pp. 144-151, 2003.

[8] J. O. G. Tande, E. Muljadi, O. Carlson, J. Pierik, A. Estanqueiro, P. Sørensen, M. O'Malley, A. Mullane, O. A. Lara, and B. Lemstrom, "Dynamic models of wind farms for power system studies-statusby IEA Wind R and D Annex 21," European Wind Energy Conference and Exhibition, London, U.K, 2004.

[9] F. Milano, "PSAT, Matlab-based Power System Analysis Toolbox," 2002, available at http://thunderbox.uwaterloo.ca/_fmilano.

D. Devaraj has received his B.E. and M. E. Degree in Electrical and Electronics Engineering and Power System engineering in 1992 and 1994 respectively from Madurai Kamaraj University, Madurai, India. From 1994 to 1997, he worked as a Lecturer in Arulmigu Kalasalingam College of Engineering, krishnankoil. He received his PhD Degree from IIT Madras, Chennai in 2001. He is currently a Senior Professor in the Department of Electrical and Electronics Engineering, Kalasalingam University, Krishnankoil. He is also a Director- Power System Group, TIFAC-CORE in Network Engineering sponsored by Government of India. His research interests include Applications of Computational Intelligent Techniques, Power System Security, , Power System Optimization, Fault Diagnosis and Data Mining.

R. Jeevajyothi received her B.E. Degree in Electrical and Electronics Engineering from Bharathidasan University, Tiruchirapalli, India in 1991, M.B.A. Degree in Marketing Management from Indhira Gandhi National Open University in 1998. and the M. E. Degree in Energy Engineering from Anna University, Chennai, India in 2006. She is pursuing Ph.D in Kalasalingam University, Krishnankoil. Her research interests include grid integration of wind energy converters. 
International Journal of Computer and Electrical Engineering, Vol.4, No.2, April 2012 